\title{
Interferência de picão-preto e guanxuma com a soja: efeitos da densidade de plantas e época relativa de emergência
}

\author{
Interference of hair beggarticks and arrowleaf sida with soybeans: effects of plant density \\ and relative emergence time
}

\author{
Nilson Gilberto Fleck ${ }^{1}$ Mauro Antônio Rizzardi ${ }^{2}$ \\ Dirceu Agostinetto $^{3}$ Alvadi Antônio Balbinot Junior ${ }^{3}$
}

\section{RESUMO}

\begin{abstract}
O objetivo deste trabalho foi avaliar as influências de densidades de picão-preto (Bidens pilosa L.) e guanxuma (Sida rhombifolia L.) e de épocas de sua emergência em relação à da soja, no grau de interferência que ocasionam à cultura. Foram realizados experimentos em duas condições em Porto Alegre - RS, em 1998/99 e 1999/00. Os fatores testados foram espécies e densidade de plantas daninhas $e$ épocas de emergência. A convivência das plantas daninhas com a soja deu-se durante a fase vegetativa da cultura. Em experimentos em vasos, avaliaram-se cinco épocas de emergência das plantas daninhas (11, 7, 2 dias antes e 4 e 8 dias após a emergência da soja). Em microparcelas, avaliaram-se três épocas de emergência das plantas daninhas em relação à soja (4 dias antes, no mesmo dia e 4 dias após) e seis densidades de plantas daninhas $(0,4,8,16,32$ e 64 plantas $\mathrm{m}^{-2}$ ). Verificou-se que a época de emergência das plantas daninhas em relação à soja modifica as relações de competição entre essas espécies e que picão-preto exerce maior efeito de competição à soja e é menos afetado pela presença da cultura do que guanxuma. O atraso na emergência da soja em relação às plantas daninhas aumenta os efeitos negativos dessas sobre a cultura, os quais são potencializados pelo incremento da densidade, principalmente no caso de picão-preto.
\end{abstract}

Palavras-chave: Bidens pilosa, Sida rhombifolia, habilidade competitiva, características de planta.

\section{ABSTRACT}

The objective of this research was to evaluate the effects of hairy beggarticks (Bidens pilosa L.) and arrowleaf sida (Sida rhombifolia L.) densities and relative emergence time, on the degree of interference they may cause on soybeans.
There were studies carried out under two conditions in Porto Alegre, RS, Brazil, in 1998/99 and 1999/00. The factors tested were weed species, emergence times, and weed densities. Weedsoybean associations occurred during the vegetative period of the crop. In pot assays, five weed emergence times were evaluated (11, 7, and 2 days before, and 4 and 8 days after soybean emergence). In microplot assays, three weed emergence times were compared in relation to soybeans (4 days before, at the same day, and 4 days after) and six weed densities $\left(0,4,8,16,32\right.$ and 64 plants $\left.\mathrm{m}^{-2}\right)$. It was found that weed relative emergence time, in relation to soybeans, modifies competitive relations between these species, and that beggarticks performs greater competition effects on soybean and is less affected by the crop than is sida. Delay in soybean emergence in relation to weeds increases the negative effects of these species on the crop, which are potentialized by increase in weed density, mainly in presence of beggarticks.

Key words: Bidens pilosa, Sida rhombifolia, competition hability, plant characteristics.

\section{INTRODUÇÃO}

Com o intuito de racionalizar a utilização de herbicidas na agricultura, há necessidade de se definir limiares econômicos que justifiquem a utilização do controle químico. A maior limitação em se estimar perdas de rendimento com base na densidade de plantas daninhas encontra-se na competitividade diferencial das infestantes em função da época relativa de sua emergência e estabelecimento junto à cultura (BERTI \& ZANIN, 1997). Em muitos casos, a época de

\footnotetext{
${ }^{1}$ Engenheiro Agrônomo, PhD, Professor do Departamento de Plantas de Lavoura da Faculdade de Agronomia da Universidade Federal do Rio Grande do Sul (UFRGS). Bolsista do CNPq. E.mail:fleck@ufrgs.br.

${ }^{2}$ Engenheiro Agrônomo, Mestre, Professor da Faculdade de Agronomia e Medicina Veterinária da Universidade de Passo Fundo, CP 611, 99001-970, Passo Fundo, RS. E-mail:rizzardi@upf.tche.br. Autor para correspondência.

${ }^{3}$ Engenheiro Agrônomo, Aluno do Programa de Pós-graduação em Fitotecnia da UFRGS.
} 
emergência das plantas daninhas em relação à cultura representa um fator mais importante em definir seu potencial competitivo do que a própria densidade de indivíduos (O'DONOVAN et al., 1985; VANDEVENDER et al., 1997).

Os efeitos negativos das plantas daninhas sobre o rendimento da cultura usualmente decrescem com o decorrer do intervalo de tempo entre emergência da cultura e das plantas daninhas. As plantas que emergirem mais tarde do que a cultura provavelmente terão menor impacto sobre o rendimento, pois grande parte da interferência ocorrerá após a determinação dos componentes do rendimento (VANDEVENDER et al., 1997). Ao trabalharem com Avena fatua L., O’DONOVAN et al. (1985) observaram que, para cada dia que a planta daninha emergiu antes da cultura, a perda no rendimento aumentou em aproximadamente 3\%. Em soja, SHURTLEFF \& COBLE (1985) constataram redução no crescimento e na altura de plantas daninhas quando as mesmas foram semeadas duas semanas após a soja, em comparação com a semeadura das infestantes duas semanas antes da soja. Essas respostas evidenciam que a época de emergência da cultura influencia a intensidade com que ela suprime as plantas daninhas. Para O'DONOVAN et al. (1985), as espécies daninhas que emergem mais cedo obtêm vantagem sobre aquelas que emergem mais tarde e tornam-se melhores competidoras por recursos do ambiente; porém, tal efeito pode não ocorrer de forma igual para todas as espécies de plantas daninhas (PAOLINI et al., 1998).

Segundo STAHLMAN \& MILLER (1990), a emergência precoce de Bromus tectorum L., em altas densidades, reduziu mais o rendimento de trigo do que a emergência tardia. Em milho, MASSINGA et al. (2001) verificaram que 0,5 planta $\mathrm{m}^{-1} \mathrm{de}$ Amaranthus palmeri S. Wats., emergindo simultaneamente com o milho, apresentou maior efeito negativo sobre o rendimento da cultura do que oito plantas daninhas que emergiram mais tarde. As interações observadas da época de emergência, com a densidade de plantas daninhas (STAHLMAN \& MILLER, 1990; MASSINGA et al., 2001) podem influenciar a comparação de experimentos que avaliem a interferência cultura-plantas daninhas. Nesse contexto, LUTMAN et al. (2000) salientam que as diferenças em perdas de rendimento causadas por plantas daninhas, verificadas entre experimentos, decorrem mais de diferenças na época de emergência das plantas daninhas do que da densidade das mesmas. Ao trabalharem com beterraba-açucareira, KROPFF \& LOTZ (1992) verificaram que diferenças em densidades de plantas daninhas, entre os experimentos, representaram $13 \%$ das variações observadas, enquanto diferenças nas épocas entre emergência da cultura e das plantas daninhas explicaram $96 \%$ das variações em perdas de rendimento.

O objetivo deste trabalho foi avaliar as influências de densidades de picão-preto e guanxuma e de épocas de sua emergência em relação à soja, no grau de interferência que ocasionam à cultura, em termos de características de planta.

\section{MATERIAL E MÉTODOS}

Os experimentos foram conduzidos em vasos e em campo, na Faculdade de Agronomia da Universidade Federal do Rio Grande do Sul (FA/ UFRGS), em Porto Alegre - RS, em 1998/99 e 1999/00.

\section{Experimentos em casa de vegetação}

Os experimentos foram instalados utilizando como parcelas vasos com capacidade volumétrica para $8 \mathrm{~L}$, e altura de $25 \mathrm{~cm}$. Num deles, avaliou-se soja convivendo com guanxuma (Sida rhombifolia L.) e, no outro, convivendo com picãopreto (Bidens pilosa L.). O delineamento experimental utilizado foi completamente ao acaso, em esquema fatorial, com quatro repetições. Os fatores investigados foram cinco épocas de emergência das plantas daninhas em relação à da soja $(11,7$ e 2 dias antes e 4 e 8 dias após a emergência da soja).

Em cada vaso, mantiveram-se quatro plantas de planta daninha e duas de soja, dispostas aleatoriamente no vaso e, convivendo com a fase vegetativa de crescimento da soja, durante o período de outubro de 1998 a janeiro de 1999 . Foram mantidas quatro testemunhas sem a presença das plantas daninhas. Nos dois experimentos, utilizou-se a cultivar de soja FT-Abyara. Antecedendo a semeadura das plantas daninhas, suas sementes foram pré germinadas em laboratório para garantir que tivessem emergência uniforme nos vasos em cada uma das épocas testadas. Utilizou-se solo oriundo da área experimental da FA/ UFRGS, classificado como Argissolo Vermelho Distrófico típico. A análise do solo indicou a presença de $240 \mathrm{~g}$ de argila por kg de solo; $\mathrm{pH}$ (água) de 4,8; 45 $\mathrm{mg}$ de $\mathrm{P}_{2} \mathrm{O}_{5}$ por $\mathrm{L} ; 120 \mathrm{mg}$ de $\mathrm{K}_{2} \mathrm{O}$ por $\mathrm{Le} 2,4 \mathrm{~g}$ de matéria orgânica por kg de solo.

A cobertura folhar da superfície do solo por plantas daninhas e cultura foi avaliada de forma ótica, aos 14 DAE da soja, através da análise de fotos tiradas em cada vaso, conforme metodologia descrita por RIZZARDI (2002). Nas fotos, a avaliação da cobertura consistiu na utilização de uma grade quadriculada com 12 pontos marcados em lâmina transparente, a qual era superposta às fotos e anotado 
o número de interseções (pontos) que se sobrepunham às folhas das plantas.

As plantas de soja e das plantas daninhas foram colhidas 60 dias após a emergência (DAE) da soja. Nessa ocasião, procedeu-se avaliações de altura de planta e matéria seca da parte aérea das plantas daninhas e altura de planta, número de folhas no caule, número de ramos laterais e matéria seca da soja.

Aos dados coletados foi aplicada análise de regressão entre emergência da planta daninha em relação à da soja como variável independente e valores das variáveis avaliadas, expressos em porcentagem, como variáveis dependentes. Os resultados são expressos em porcentagem e foram calculados com base nos valores das parcelas testemunhas, nas quais não havia infestação de plantas daninhas.

\section{Experimentos em campo}

Dois experimentos foram instalados em microparcelas em campo, um destinado ao picão-preto e outro à guanxuma, espécies que conviveram com a soja durante a fase vegetativa de crescimento da cultura.

$\mathrm{O}$ delineamento experimental utilizado em ambos os experimentos foi completamente casualizado, em esquema fatorial, com quatro repetições. Nesses experimentos foram avaliadas três épocas de emergência das plantas daninhas em relação à soja (4 dias antes, no mesmo dia e 4 dias após) e seis densidades de plantas daninhas $\left(0,4,8,16,32\right.$ e 62 plantas $\left.\mathrm{m}^{-2}\right)$. As unidades experimentais, em número de 72 por experimento, foram demarcadas em área semeada homogeneamente com soja, cujas fileiras estiveram espaçadas entre si a $0,4 \mathrm{~m}$. Cada unidade experimental apresentou $0,25 \mathrm{~m}^{2}(0,8 \mathrm{~m} \mathrm{x}$ $0,31 \mathrm{~m})$.

A área na qual foi conduzido o experimento possui solo classificado como Argissolo Vermelho Distrófico típico. A análise do solo indicou a presença de $240 \mathrm{~g}$ de argila por $\mathrm{kg}$ de solo; $\mathrm{pH}$ (água) de 4,9; $48 \mathrm{mg}$ de $\mathrm{P}_{2} \mathrm{O}_{5}$ por L; $115 \mathrm{mg}$ de $\mathrm{K}_{2} \mathrm{O}$ por $\mathrm{L}$ e $2,5 \mathrm{~g}$ de matéria orgânica por $\mathrm{kg}$ de solo. Antecedendo a semeadura da soja, adubouse o solo mediante aplicação a lanço de $15 \mathrm{~kg}$ de N ha $^{-1}$, 60kg de $\mathrm{P}_{2} \mathrm{O}_{5}$ ha $^{-1}$ e $60 \mathrm{~kg}$ de $\mathrm{K}_{2} \mathrm{O} \mathrm{ha}^{-1}$ (300kg ha${ }^{1}$ da fórmula 05-20-20). Em seguida, preparou-se e incorporou-se os fertilizantes ao solo através de aração seguida de gradagem. As sementes de soja foram inoculadas com Bradyrhizobium japonicum (SEMIA 5019) e tratadas com o fungicida thiram (70 $100 \mathrm{~kg}^{-1}$ de sementes). A cultivar reagente de soja foi Embrapa 66, semeada manualmente na mesma época em todas as parcelas em 01/12/99, em espaçamento entrelinhas de $0,4 \mathrm{~m}$ e densidade de
40 plantas $\mathrm{m}^{-2}$.

Para simular cada uma das épocas de emergência das plantas daninhas em relação à soja, sementes das plantas daninhas foram pré-germinadas a $30^{\circ} \mathrm{C}$ durante 48 horas e, então, transferidas para células contendo solo peneirado e umedecido. Quando do aparecimento dos cotilédones na superfície do solo, aproximadamente três dias após o início do processo, as plântulas foram distribuídas aleatoriamente nas microparcelas. Para garantir o estabelecimento das populações de plantas desejadas, fez-se o transplante do dobro de cada população-alvo. O desbaste das plantas excedentes e o ajuste da população de soja foram realizados 7 dias após o transplante das plantas daninhas.

No estádio de início do florescimento da soja, aos 60 DAE, procedeu-se a colheita do experimento, quando foram realizadas avaliações de matéria seca da parte aérea da soja, em cinco plantas de soja por microparcela, e de matéria seca da parte aérea das plantas daninhas de cada unidade experimental. Após a colheita, as plantas da cultura e das plantas daninhas foram postas a secar em estufa com circulação forçada de ar, à temperatura de $60^{\circ} \mathrm{C}$, até atingirem peso constante, com posterior pesagem do material.

Os dados coletados nos experimentos foram submetidos à análise de variância. Quando significativo o teste $\mathrm{F}$ ( $\mathrm{p} \leq 0,05$ para efeitos principais e $\mathrm{p} \leq 0,15$ para interações), foi realizada análise de regressão entre a variável-resposta e a densidade de plantas, para o que foram utilizados modelos polinomiais linear e quadrático.

\section{RESULTADOS E DISCUSSÃO}

Ao se analisar a figura 1, verifica-se que, à medida em que a emergência das plantas daninhas antecipou-se à emergência da soja, maior foi o impacto negativo que causaram às variáveis associadas às plantas de soja. Para presença de picão-preto, o impacto negativo foi observado nas variáveis de soja número de folhas no caule, matéria seca e, principalmente, número de ramos laterais. No caso de presença de guanxuma, todas as variáveis avaliadas em soja foram afetadas pela presença da espécie mas, geralmente, em percentuais inferiores àqueles observados com picão-preto.

A maior intensidade do efeito negativo observado nas emergências das plantas daninhas antes da cultura relaciona-se ao fato de que nessa condição elas exercem prioridade na utilização dos recursos do ambiente e, em consequiência, formam plantas com porte mais elevado e com maior potencial competitivo. 


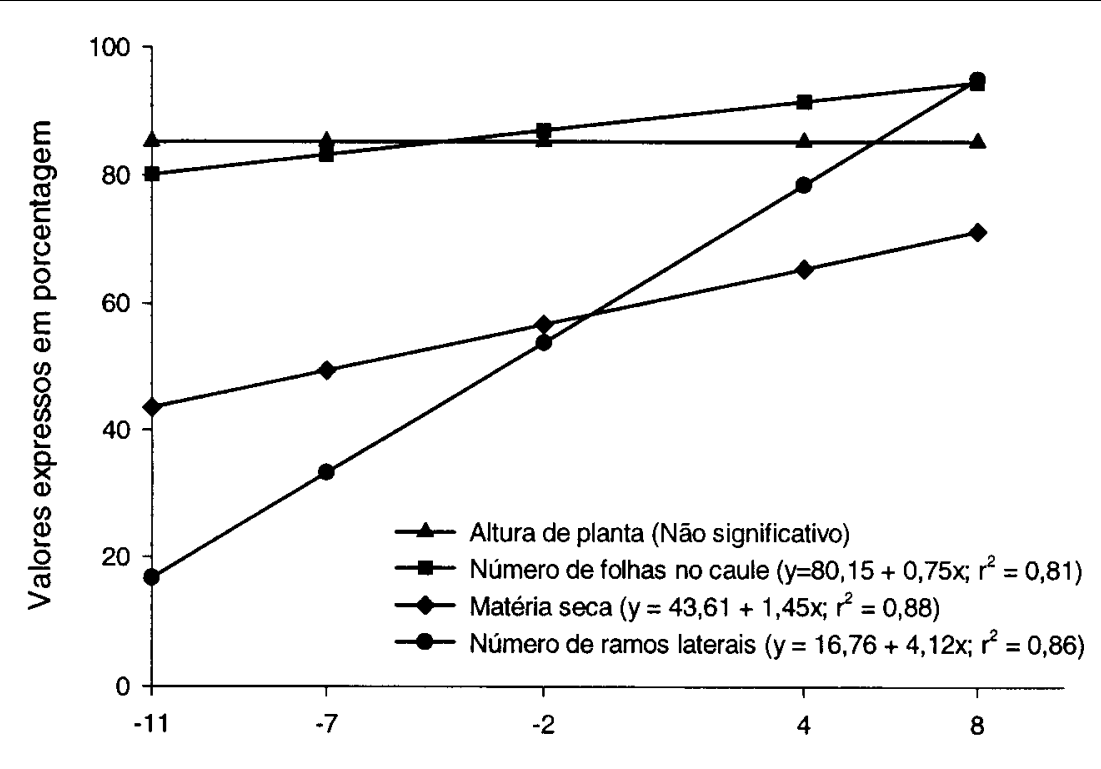

Emergência de picão-preto em relação à soja (dias)

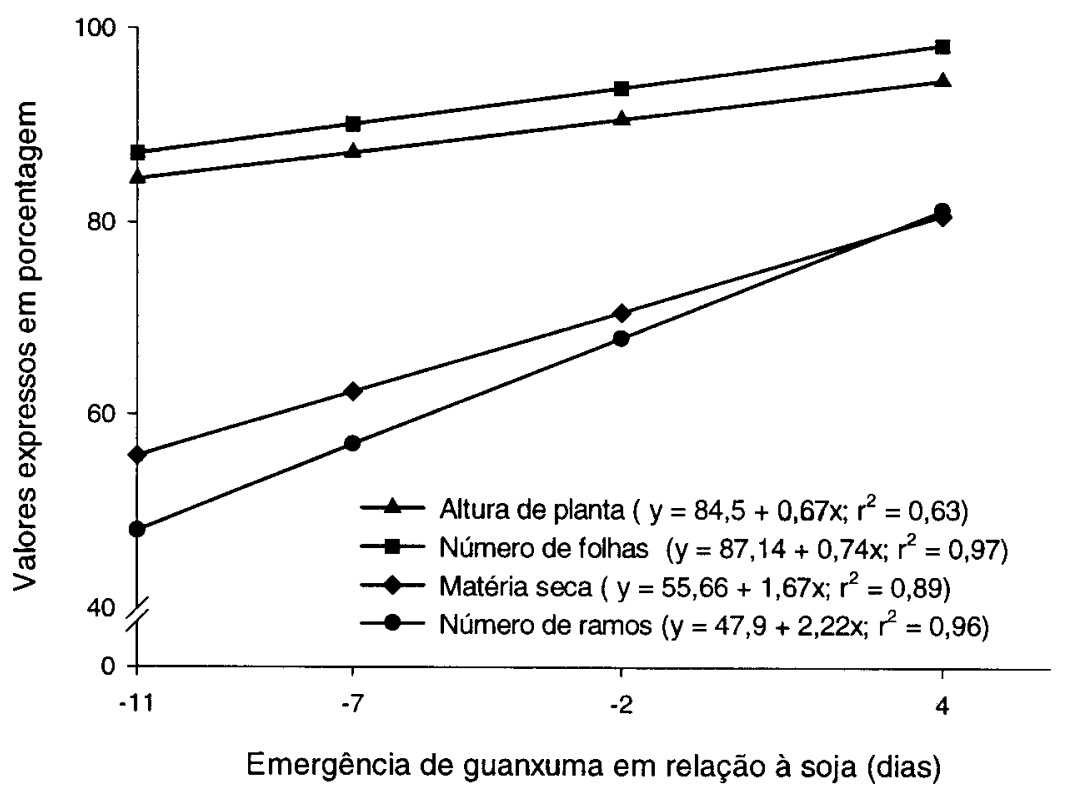

Figura 1 - Efeitos de épocas relativas de emergência de picão-preto e guanxuma em características de planta de soja, UFRGS, Porto Alegre, RS, 1998/99.

Resultados similares foram obtidos em trabalhos dessa natureza por O'DONOVAN et al. (1985) e SHURTLEFF \&COBLE(1985).

Em relação aos efeitos da cultura sobre as plantas daninhas, verificou-se que, à medida que atrasou a época de emergência das plantas daninhas em relação à da soja, reduziram-se os valores das variáveis da planta daninha, como matéria seca, altura de planta e cobertura do solo (Figura 2). No caso de guanxuma, a partir da emergência da planta daninha dois dias antes da soja, as perdas percentuais das variáveis avaliadas se estabilizaram, como caracterizado pelo melhor ajuste do modelo quadrático às variáveis avaliadas. Essa maior supressão no desenvolvimento da guanxuma pela soja associa-se, provavelmente, ao crescimento inicial 

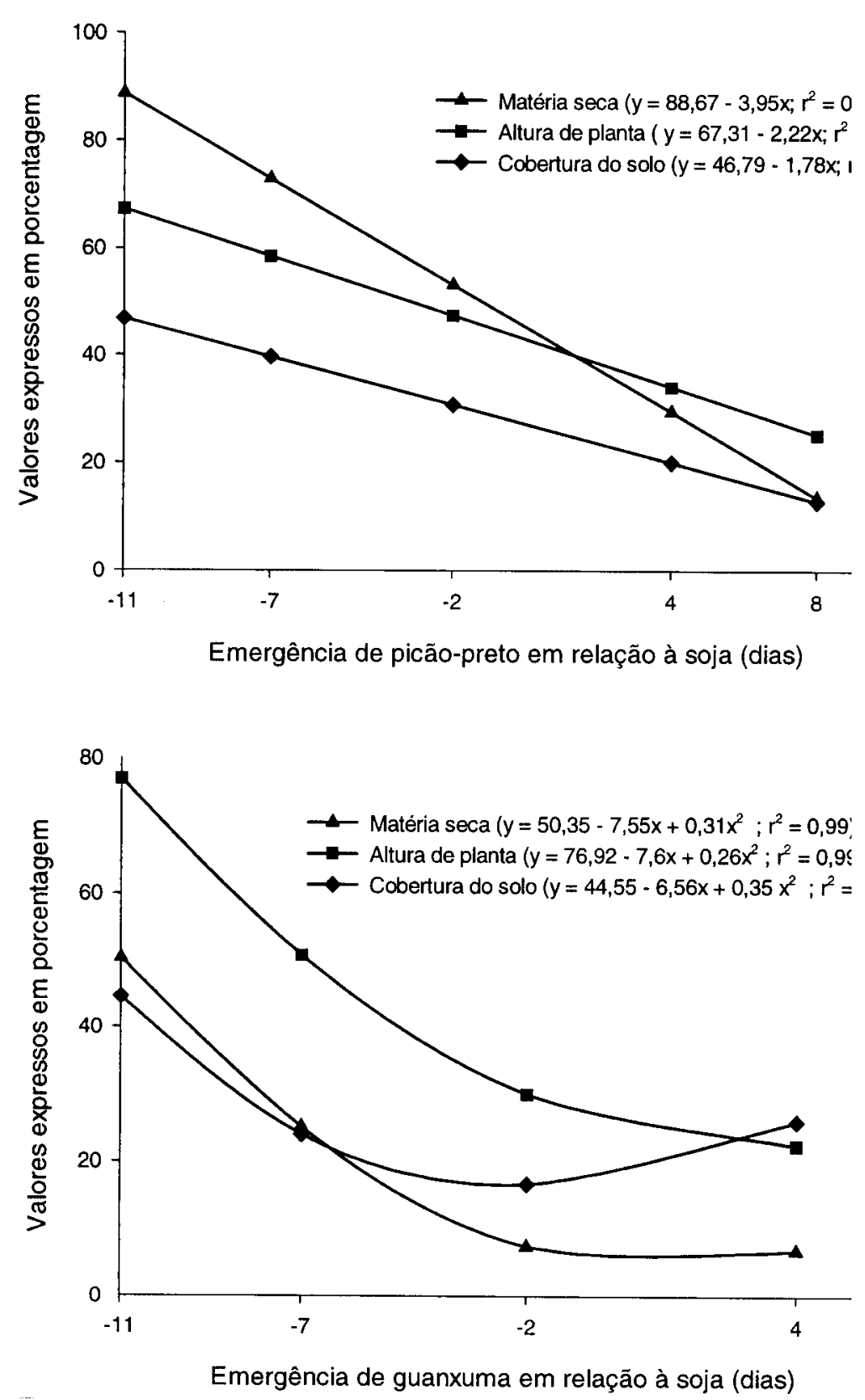

Figura 2 - Influência da época relativa de emergência de picão-preto e guanxuma, em relação à da soja, sobre características das plantas daninhas, UFRGS, Porto Alegre, RS, 1998/99.

mais lento dessa planta daninha quando comparado com a soja, ou mesmo com picão-preto. O ponto crucial no incremento competitivo de uma espécie em relação à outra deve-se à taxa de crescimento inicial, em que a espécie que apresentar maior taxa dominará a utilização dos recursos que ficam indisponíveis para a espécie concorrente (JOHNSON et al., 1998).
Os efeitos das variações na época de emergência das plantas daninhas nas respostas da soja às densidades de picão-preto e guanxuma podem ser visualizados na figura 3. Para picão-preto, houve interação de época de sua emergência em relação à soja com densidade da planta daninha. No geral, à medida em que picão-preto emergiu antes da soja ocorreram efeitos negativos mais intensos, os quais foram reforçados pelo 

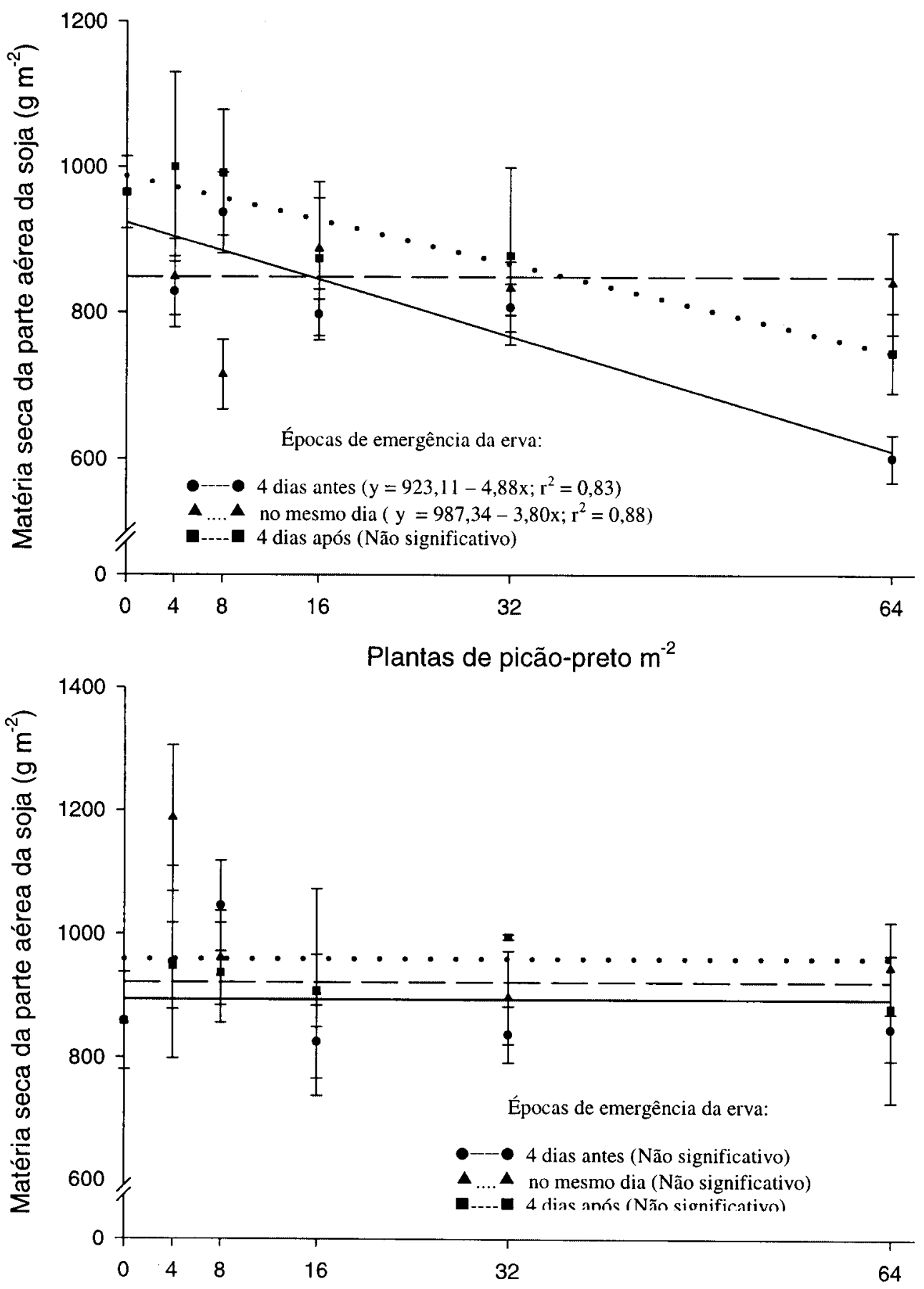

Plantas de guanxuma $\mathrm{m}^{-2}$

Figura 3 - Matéria seca de plantas de soja em função de densidades de plantas de picão-preto e de guanxuma e de épocas relativas de emergência das plantas daninhas em relação à soja, UFRGS, Porto Alegre - RS, 1999/00. (Barras verticais representam erro padrão da média).

Ciência Rural, v.34, n.1, jan-fev, 2004. 
aumento da densidade da planta daninha. Resultados similares foram obtidos por BLACKSHAW (1993), em que as reduções de matéria seca e rendimento de grãos de centeio aumentaram mais intensamente com o incremento da densidade de plantas quando a planta daninha emergiu junto com o centeio, em comparação com sua emergência três semanas após.

Observa-se que, na emergência de picão-preto quatro dias antes da soja, houve redução de $4,9 \mathrm{~g} \mathrm{~m}^{-2}$ de matéria seca para cada acréscimo unitário de planta da erva, ocasionando redução percentual total de $38 \%$ na matéria seca com o incremento da densidade de zero para 64 plantas $\mathrm{m}^{-2}$. Para emergência simultânea da planta daninha e da soja, a redução foi de $3,8 \mathrm{~g} \mathrm{~m}^{-2}$, perfazendo perda global de $23 \%$. Já na emergência da planta daninha quatro dias após a soja, não se observou efeito significativo de densidade, embora tivesse ocorrido redução média de $13 \%$ na produção de matéria seca com o incremento da população de picão-preto de zero para 64 plantas $\mathrm{m}^{-2}$.

Em relação à guanxuma, os resultados não demonstraram efeitos nem de densidades e nem de épocas de emergência sobre a matéria seca da soja. Para essa planta daninha, em determinadas densidades, ocorreram, inclusive, maiores valores absolutos de matéria seca em comparação ao tratamento sem plantas daninhas (Figura 3), a exemplo do que foi referido para ocorrência de valores negativos para perdas de rendimento de grãos de soja em convivência com plantas daninhas (RIZZARDI, 2002).

A habilidade competitiva demonstrada pela soja em relação ao picão-preto e guanxuma pode ser analisada adicionalmente observando a figura 4. Para ambas as plantas daninhas, o incremento nas densidades de plantas aumentou suas respectivas produções de matéria seca de forma mais intensa quando a emergência das plantas daninhas se antecipou à da soja. Os aumentos foram gradativamente reduzidos quando as plantas emergiram mais tarde, principalmente para guanxuma. A capacidade de supressão de plantas daninhas por plantas cultivadas decorre do fato que culturas que apresentam acelerado crescimento inicial e uniformidade de ocupação do nicho ecológico, possuem alta capacidade de sombrear precocemente as plantas daninhas, diminuindo, dessa forma, a quantidade e a qualidade da luz incidente sobre as mesmas (ALTIERI \& LIEBMAN, 1988).

De forma geral, a análise dos experimentos permite concluir que o grau de interferência negativa exercido por plantas daninhas dicotiledôneas na cultura da soja depende da espécie presente e da densidade populacional em que ocorre; mas, sobretudo, conclui-se que esses fatores são fortemente modificados pela época de emergência das plantas daninhas em relação à cultura. Do ponto de vista prático, pouco pode-se fazer em relação à inibição completa da emergência de plantas daninhas, além da adoção de práticas de manejo, como não revolvimento do solo e agregação de palha ao sistema, para reduzir o fluxo de emergência. Por outro lado, muito pode ser feito visando possibilitar rápido estabelecimento da cultura, como uso de sementes certificadas, com alto

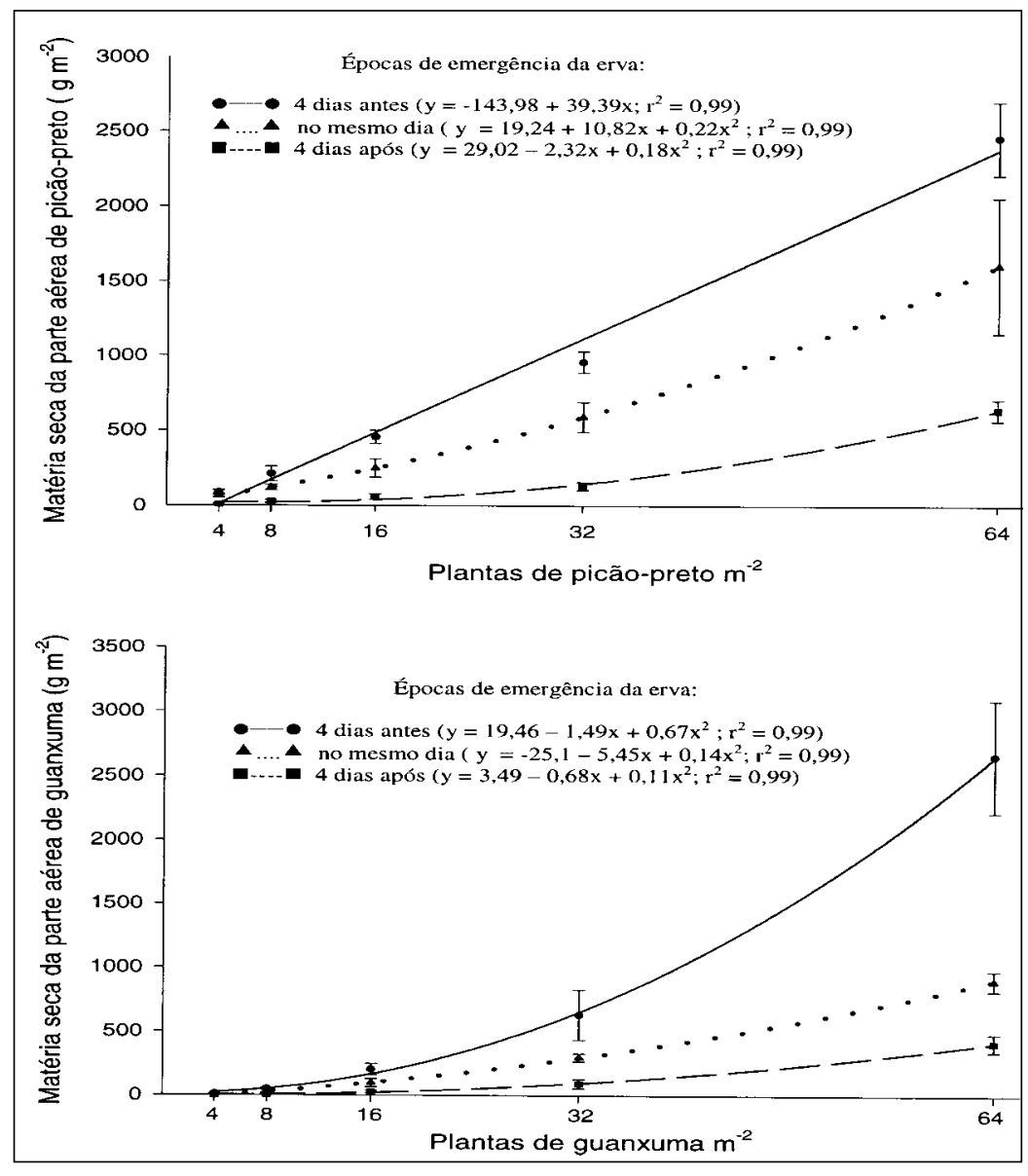

Figura 4 - Matéria seca de plantas de picão-preto e de guanxuma em função de densidades de plantas daninhas e de épocas relativas de emergência em relação à soja, UFRGS, Porto Alegre - RS, 1999/00. (Barras verticais representam erro padrão da média). 
poder germinativo e vigor, e semeadura da cultura em condições mais favoráveis ao seu potencial de competição, fora do período mais adequado à germinação das plantas daninhas. Para isso, é importante conhecer o padrão de germinação das plantas daninhas em diferentes condições de ambiente e avaliar o impacto da alteração na época de emergência sobre a capacidade competitiva da cultura em relação às plantas daninhas.

\section{CONCLUSÕES}

A soja mostra habilidade em competir com picão-preto e guanxuma durante a fase de crescimento vegetativo.

A espécie picão-preto interfere nas características de planta da soja em maior intensidade do que guanxuma.

A época de emergência de picão-preto e guanxuma em relação à soja modifica as relações de competição entre essas espécies.

O atraso na emergência da soja em relação ao picão-preto e guanxuma aumenta os efeitos negativos dessas espécies sobre a cultura, os quais são potencializados pelo incremento da densidade, principalmente para picão-preto.

\section{REFERÊNCIAS BIBLIOGRÁFICAS}

ALTIERI, M.A.; LIEBMAN, M. Weed management in agroecosystems: ecological approaches. Boca Raton: CRC, 1988. $354 \mathrm{p}$.

BERTI, A.; ZANIN, G. GESTINF: a decision model for postemergence weed management in soybean (Glycine max (L.) Merr.). Crop Protection, Surrey, v.16, n.2, p.109-116, 1997.

BLACKSHAW, R.E. Downy brome (Bromus tectorum) interference in winter rye (Secale cereale). Weed Science, Champaign, v.41, n.4, p.557-562, 1993.
KROPFF, M.J.; LOTZ, L.A.P. Optimization of weed management systems: the role of ecological models of interplant competition. Weed Technology, Champaign, v.6, n.2, p.462-470, 1992

JOHnSON, D.E.; DINGKUHN, M.; JONES, M.P. The influence of rice plant type on the effect of weed competition on Oryza sativa and Oryza glaberrima. Weed Research, Oxford, v.38, n.3, p.207-216, 1998.

LUTMAN, P.J.W. et al. Prediction of competition between oilseed rape and Stellaria media. Weed Research, Oxford, v.40, n.3, p.255-269, 2000.

MASSINGA, R.A. et al. Interference of palmer amaranth in corn. Weed Science, Lawrence, v.49, n.2, p.202-208, 2001.

O'DONOVAN, J.T. et al. Influence of the relative time of emergence of wild oat (Avena fatua) on yield loss of barley (Hordeum vulgare) and wheat (Triticum aestivum). Weed Science, Champaign, v.33, n.4, p.498-503, 1985.

PAOLINI, R. et al. Competition between safflower and weeds as influenced by crop genotype and sowing time. Weed Research, Oxford, v.38, n.4, p.247-255, 1998.

RIZZARDI, M.A. Nível de dano econômico para tomada de decisão no controle de picão-preto (Bidens spp.) e guanxuma (Sida rhombifolia L.) na cultura da soja. 2002. 176f. Tese (Doutorado em Fitotecnia Plantas de Lavoura) - Universidade Federal do Rio Grande do Sul.

SHURTLEFF, J.L.; COBLE, H.D. Interference of certain broadleaf weed species in soybeans (Glycine max). Weed Science, Champaign, v.33, n.5, p.654657,1985 .

STAHLMAN, P.W.; MILLER, S.D. Downy brome (Bromus tectorum) interference and economic thresholds in winter wheat (Triticum aestivum). Weed Science, Champaign, v.38, n.3, p.224-228, 1990.

VANDEVENDER, K.W.; COSTELLO, T.A.; SMITH JR., R.J. Model of rice (Oryza sativa) yield reduction as a function of weed interference. Weed Science, Lawrence, v. 45, n.2, p.218-224, 1997. 